\title{
Reduction of HbA1c levels by fucoxanthin-enriched akamoku oil possibly involves the thrifty allele of uncoupling protein 1 (UCP1): a randomised controlled trial in normal-weight and obese Japanese adults
}

\author{
Nana Mikami ${ }^{*}$, Masashi Hosokawa ${ }^{2}$, Kazuo Miyashita $^{2}$, Hitoshi Sohma ${ }^{1,3}$, \\ Yoichi M. Ito ${ }^{4}$ and Yasuo Kokai ${ }^{1}$ \\ ${ }^{1}$ Department of Biomedical Engineering, Sapporo Medical University School of Medicine, S1W17, Chuo-ku, Sapporo, Hokkeaido, Japan \\ ${ }^{2}$ Faculty of Fisheries Sciences, Hokkaido University, Minato-cho 3-1-1, Hakodate, Hokkaido, Japan \\ ${ }^{3}$ Department of Educational Development, Sapporo Medical University Center for Medical Education, S1W17, Chuo-ku, Sapporo, Hokkeaido, \\ Japan \\ ${ }^{4}$ Department of Biostatistics, Hokkaido University Graduate School of Medicine, N15W7, Kita-ku, Sapporo, Hokkaido, Japan
}

(Received 26 September 2016 - Accepted 3 January 2017)

Journal of Nutritional Science (2017), vol. 6, e5, page 1 of 9

doi:10.1017/jns.2017.1

Abstract

Lifestyle-related problems are becoming a major health threat in East Asian countries. Therefore, finding an efficacious nutraceutical for this population is important. One candidate is fucoxanthin (Fx), a carotenoid abundantly found in edible brown seaweed that has been associated with a number of valuable health-promoting benefits. Unfortunately, clinical studies of Fx are limited. In the present study, we aimed to evaluate the effects of Fx on obesity-related parameters in Japanese subjects harbouring an SNP associated with lifestyle-related problems. In all, sixty normal-weight and obese Japanese adults with BMI over $22 \mathrm{~kg} / \mathrm{m}^{2}$ were single-blinded and randomly assigned to three Fx-dose cohorts and administered Fx-enriched akamoku oil containing Fx at 0,1 or $2 \mathrm{mg} / \mathrm{d}$ for 8 weeks ( 20 per group). Parameters relating to obesity and serum Fx metabolites were measured before and after intervention, but no significant differences were observed between and within the groups. Despite no changes in visceral fat areas and resting energy expenditures after intervention, we observed a significant decline in HbA1c levels in the $2 \mathrm{mg} / \mathrm{d}$ Fx group compared with that in the $0 \mathrm{mg} / \mathrm{d}$ group $(P<0 \cdot 05)$, which was correlated with an increase in serum fucoxanthinol (Fx metabolite) levels. In addition, HbA1c levels declined more significantly in subjects with $G / G$ alleles of the uncoupling protein 1 (UCP1) gene than in those with the A/A and $\mathrm{A} / \mathrm{G}$ alleles $(P<0 \cdot 05)$. We conclude that although Fx supplementation does not affect visceral fat areas, it may reduce HbA1c levels in those harbouring the thrifty allele of $U C P 1-3826 \mathrm{~A} / \mathrm{G}$.

Key words: UCP1-3826A/G polymorphism: Fucoxanthin: HbA1c: Thrifty gene: Japanese: Diabetes: Glucose metabolism

Fucoxanthin $(\mathrm{Fx})$ is a marine carotenoid widely found in edible brown algae such as wakame (Undaria pinnatifida), kombu (Laminaria japonica) and akamoku (Sargassum horneri). It constitutes more than $10 \%$ of naturally produced carotenoids ${ }^{(1)}$, providing an abundant reserve of unutilised resources in the ocean. Out of the fifteen species of brown algae that have been studied, akamoku contains the highest content of $\mathrm{Fx}^{(2)}$, making it an excellent source for the raw material in our study.

Fx has demonstrated beneficial effects against obesity ${ }^{(3,4)}$, diabetes $^{(5)}$ and cancer ${ }^{(6)}$. However, despite proven effects in animal studies, only a few studies on kinetics ${ }^{(7,8)}$ and obesity ${ }^{(9)}$ have been conducted in human subjects. There is one report

Abbreviations: $\beta 2 A R, \beta 2$-adrenoreceptor gene; $\beta 3 A R, \beta 3$-adrenoreceptor gene; Fx, fucoxanthin; FxOH, fucoxanthinol; REE, resting energy expenditure; UCP1, uncoupling protein 1.

*Corresponding author: N. Mikami, fax +81 11615 2315, email mikami7@sapmed.ac.jp 
demonstrating that the supplement Xanthigen ${ }^{\circledR}$, a product that contains Fx and pomegranate seed oil, induces weight loss and body fat reduction, and increases resting energy expenditure (REE) in obese women ${ }^{(9)}$. However, that study was based on the Caucasian population in Russia; thus, the supplement's effects on East Asian populations remain unclear. Furthermore, no reports have evaluated Fx absorption, serum metabolite (fucoxanthinol; $\mathrm{FxOH}$ ) levels and functionality. Our study will help expand the knowledge base in these areas.

Although inactive, food-satiated lifestyles dramatically increase the incidence of obesity and related metabolic disorders, the interaction between environmental and genetic factors greatly influences health and susceptibility to disease ${ }^{(10)}$. Therefore, a tailored nutritional approach based on the individual and the population's genetic background, as characterised by SNP analysis, is required to consider the effectiveness of nutraceuticals.

Uncoupling protein 1 (UCP1) is a thermogenic protein that dissipates glucose and lipid as heat. We investigated how Fx affects glucose metabolism with an SNP of the UCP1 gene $(-3826 \mathrm{~A} / \mathrm{G})^{(11)}$, the thrifty $\mathrm{G} / \mathrm{G}$ genotype, which is associated with the development of obesity and insulin resistance ${ }^{(12)}$. In addition, we analysed polymorphisms of other thrifty genes, $\beta 2$-adrenoreceptor $(\beta 2 A R)$ and $\beta 3$-adrenoreceptor $(\beta 3 A R)$, which also decrease energy expenditure ${ }^{(13,14)}$.

Through our research, we aimed to elucidate the role of $\mathrm{Fx}$ in the development of metabolic disorders such as obesity and diabetes, and study the effect of genetic variation in the Japanese adult population on its function.

\section{Materials and methods}

\section{Materials}

Fx capsules were purchased from Kaneka Corporation. Fx-enriched akamoku oil (containing 1\% Fx) derived from akamoku extract, and medium-chain TAG oil containing lecithin and vitamin $\mathrm{E}$ were used to manufacture the Fx soft-gel capsules. Each capsule contained Fx-enriched akamoku oil at the doses of $0 \mathrm{mg}$ (Fx $0 \mathrm{mg}$, hereafter), $110 \mathrm{mg}$ (Fx $1 \mathrm{mg}$, hereafter), or $220 \mathrm{mg}$ (Fx $2 \mathrm{mg}$, hereafter) (Table 1). All capsules appeared identical.

\section{Subjects}

A total of sixty normal-weight and obese Japanese adult men and women with BMI $\geq 22 \mathrm{~kg} / \mathrm{m}^{2}$ were included in the study in Rumoi, Hokkaido, Japan. The group consisted of twenty men and forty women who ranged in age from 30 to 77

Table 1. Composition of fucoxanthin capsules

\begin{tabular}{lccc}
\hline & \multicolumn{3}{c}{ Fucoxanthin content } \\
\cline { 2 - 4 } Composition & $0 \mathrm{mg}$ & $1 \mathrm{mg}$ & $2 \mathrm{mg}$ \\
\hline $\begin{array}{l}\text { Fucoxanthin-enriched } \\
\text { akamoku oil (1\% fucoxanthin; } \mathrm{mg})\end{array}$ & 0 & 110 & 220 \\
\begin{tabular}{l} 
Medium-chain TAG oil (mg) \\
\hline
\end{tabular} & 250 & 140 & 30 \\
\hline
\end{tabular}

years. Written informed consent was obtained from all subjects. Pregnant and lactating women and those unable to give consent were excluded from the study.

\section{Study design}

This study was an 8-week, single-centre, randomised, singleblinded, controlled clinical trial conducted from November 2013 to March 2014.

Following simple randomisation procedures (computerised random numbers) ${ }^{(15)}$, our subjects were single-blinded and randomly assigned to three treatment groups (allocation ratio, 1:1:1): Fx $0 \mathrm{mg} / \mathrm{d}$ (placebo control), $\mathrm{Fx} 1 \mathrm{mg} / \mathrm{d}$ or $\mathrm{Fx}$ $2 \mathrm{mg} / \mathrm{d}$. The subjects were told to take one capsule per $\mathrm{d}$ after dinner for 8 weeks and maintain their normal diet and physical activity.

This study was conducted according to the guidelines of the Declaration of Helsinki, and our study protocol and all procedures involving human subjects were approved by the local research ethics committee in Rumoi Cohortopia (\#13-01) and registered with the University Hospital Medical Information Network Clinical Trials Registry (trial number UMIN000020119; http://www.umin.ac.jp/). This report follows the Consolidated Standards of Reporting Trials (CONSORT) 2010 checklist (http://www.consort-statement. $\operatorname{org} /)$.

\section{Visceral fat analyses}

Before and after the 8-week supplementation period, abdominal visceral fat areas (primary outcome of this study) were measured in a supine position via computed tomography scans using an Aquilion 64 (Toshiba Medical Systems Corporation) at the Rumoi City Hospital (Hokkaido, Japan).

\section{Resting energy expenditure measurements}

Before and after the 8-week supplementation period, REE was determined with a MedGem metabolic analyser device (HealtheTech, Inc.), a portable indirect calorimeter that we used for $10 \mathrm{~min}$ (as recommended by the manufacturer) to measure $\mathrm{O}_{2}$ consumption ${ }^{(16)}$.

\section{Blood biochemical markers}

Before and after the 8-week supplementation period, blood samples were drawn after $12 \mathrm{~h}$ of fasting to assess secondary outcomes. The following levels were measured: blood glucose, HbA1c, serum insulin, total cholesterol, HDL-cholesterol, LDL-cholesterol, TAG, aspartate aminotransferase, alanine aminotransferase and $\gamma$-glutamyl transpeptidase. Glycated albumin levels were measured before and after intervention only in UCP1 G/G carriers who were administered Fx $2 \mathrm{mg} / \mathrm{d}$.

While blood glucose is the amount of glucose present in blood at any given time, glycated albumin and HbA1c (glycated $\mathrm{Hb}$ ) reflect the cumulative glycaemic history (average glycaemic levels over the previous 2 weeks and 3-4 months, respectively) ${ }^{(17)}$. Serum insulin is an indicator of insulin 
secretion in a sample population. Total cholesterol, HDLcholesterol, LDL-cholesterol and TAG reflect lipid metabolism, whereas HDL- and LDL-cholesterol, and TAG levels are used for diagnosing dyslipidaemia. Aspartate aminotransferase, alanine aminotransferase and $\gamma$-glutamyl transpeptidase are enzymes related to liver function and are used to evaluate the hepatic toxicity of Fx.

\section{Serum fucoxanthinol analysis}

To quantify serum FxOH levels (a major metabolite of $\mathrm{Fx}$ ), serum epoxyxanthophyll fractions that included $\mathrm{FxOH}$ were extracted and analysed by a liquid chromatography-tandem MS (LC-MS/MS) system as previously developed by the authors and described below. We used Fx as the internal standard because $\mathrm{Fx}_{\mathrm{x}}$ is structurally similar to $\mathrm{FxOH}^{(18)}$, the two have comparable solvent properties, and a preliminary experiment revealed that Fx is not detectable in the serum after its intake.

The extraction was performed according to the method developed by Asai et al. ${ }^{(8)}$, with a slight modification. In brief, $1 \mathrm{ml}$ of serum, $0.2 \mathrm{ml}$ of saline and $2 \mathrm{ml}$ of methanol that included $5 \mathrm{ng}$ of Fx as an internal standard were added to a glass tube and vortexed. The residue was dissolved in $n$-hexane-diethyl ether (9:1, $\mathrm{v} / \mathrm{v}$ ) and applied to a Bond Elut ALN (100 mg, $1 \mathrm{ml}$ ) solidphase extraction cartridge (Agilent Technologies) pretreated with $1 \mathrm{ml} n$-hexane. Epoxyxanthophylls eluted with $1 \mathrm{ml}$ diethyl ether-ethanol $(4: 1, \mathrm{v} / \mathrm{v})$ were dried and re-suspended in $250 \mu \mathrm{l}$ of methanol-acetonitrile (70:30, v/v), and then $50 \mu \mathrm{l}$ of the sample were subjected to LC-MS/MS analysis. Each serum sample was independently extracted and analysed in triplicate.

Our liquid chromatography system was composed of an Agilent 1100 series degasser, binary pump, auto-sampler, column oven (Agilent Technologies) and Inertsil ${ }^{\circledR}$-ODS column $(4.6 \mathrm{~mm}$ inner diameter $\times 150 \mathrm{~mm}, 3 \mu \mathrm{m}$, GL Sciences Inc.). The HPLC mobile phases were solvent A (methanol-acetonitrile, 70:30, v/v) and solvent $\mathrm{B}$ (dichloromethane). Elution after sample injection was performed as follows: 0-5 min, $0 \% \mathrm{~B}$; 5-25 min, 0-100 \% $\mathrm{B}$; $25-50 \mathrm{~min}, 100 \% \mathrm{~B}$; $50-60 \mathrm{~min}, 0 \% \mathrm{~B}$. The flow rate was maintained at $1 \mathrm{ml} / \mathrm{min}$ at $35^{\circ} \mathrm{C}$. FxOH was detected at $2.3 \mathrm{~min}$. The amount of $\mathrm{FxOH}$ in the serum was calculated from the peak area counts of the spiked internal standard.

\section{Analysis of UCP1 gene polymorphism}

For analysis of SNP, genomic DNA was isolated from wholeblood samples of each subject using a DNA solution kit (Qiagen). Polymorphisms of UCP1-3826A/G (rs1800592), $\beta 2 A R \quad 16 \mathrm{Arg} / \mathrm{Gly}$ (rs1042713) and $\beta 3 A \mathrm{R} 64 \mathrm{Trp} / \mathrm{Arg}$ (rs4994) were determined using a Toyobo Gene analysis system (Fukui) as described by Yamada et al. ${ }^{(19)}$.

\section{Statistics}

The sample size ( $n 20$ per group) was calculated from a previous study reporting a $10 \%$ reduction of body weight for obese subjects $^{(9)}$. Twenty participants were estimated to be sufficient to set the power of the trial at $80 \%$ with a significance level of
$5 \%$ for detecting significant body-weight reduction. That number allowed for a $20 \%$ dropout rate from each group.

Results are expressed as means and standard errors. Data were verified for normality by the Shapiro-Wilk test. When necessary, they were log-transformed for normal distribution before further statistical analysis for homogeneity of variance. Parametric comparisons were performed using $t$ tests, one-way ANOVA and the Tukey-Kramer test for multiple comparisons. If normal distribution and equality of variance tests were not performed, Welch's test was used, and, if necessary, a non-parametric Steel-Dwass test. For the genotype frequency of UCP1-3826A/G, Fisher's exact test was performed. For $\mathrm{G} / \mathrm{G}$ carriers administered $\mathrm{Fx} 2 \mathrm{mg} / \mathrm{d}$, albumin levels were measured before and after intervention, then analysed by paired $t$ test. In all cases, $P$ values $<0.05$ were considered statistically significant. All analyses were performed using $\mathrm{JMP}^{\circledR}$ 10.0.0 and 10.0.2 (SAS Institute Inc.) or R version 3.2.0.

\section{Results}

\section{Characteristics of subjects}

This study was a single-blinded, randomised intervention trial. A total of sixty healthy participants provided informed consent regarding the aims of this clinical trial. Allocation, follow-up and analysis are summarised in Fig. 1.

At baseline, the subjects were evenly distributed in terms of age, sex, BMI, visceral fat area, REE and all blood biochemical markers (Table 2). Overall, the mean age was 55 (SE 2) years (range 30-77 years) and the mean BMI was 26.4 (SE 0.4) $\mathrm{kg} / \mathrm{m}^{2}$ (range $22.4-34.9 \mathrm{~kg} / \mathrm{m}^{2}$ ). Because the Japan Society for the Study of Obesity defines $18.5 \leqq \mathrm{BMI}<25 \mathrm{~kg} / \mathrm{m}^{2}$ as normal weight and $\mathrm{BMI} \geqq 25 \mathrm{~kg} / \mathrm{m}^{2}$ as obese ${ }^{(20)}$, our population included twenty-six normal-weight and thirty-three obese subjects. One man in the Fx $1 \mathrm{mg} / \mathrm{d}$ group dropped out for private reasons. The follow-up rate was $98.3 \%$, and no adverse events were reported. After intervention, no significant differences for any of the parameters were observed among the three groups (Table 2). Furthermore, comparisons within groups (baseline $v$. after intervention) also revealed no significant differences (Table 2).

\section{Fucoxanthin did not change obesity-related outcomes}

Fx intervention did not change visceral fat areas (change in the Fx 0, 1 and $2 \mathrm{mg} / \mathrm{d}$ groups were -6.6 (SE 3.6), -8.6 (SE 5.4) and -5.7 (SE 3.4$) \mathrm{cm}^{2}$, respectively). Other obesity-related outcomes such as body weight, BMI and REE also remained unchanged in the Fx groups.

Fucoxanthin reduced HbA1c and increased serum fucoxanthin metabolite levels

Detailed analysis of biochemical parameters revealed a significant reduction in $\mathrm{HbA} 1 \mathrm{c}$ in the $\mathrm{Fx}_{\mathrm{x}} 2 \mathrm{mg} / \mathrm{d}$ group $(-0.14$ (SE 0.0$) \%$ compared with that of the $0 \mathrm{mg} / \mathrm{d}$ group $(0.06$ (SE 0.05$) \%, P<0 \cdot 05$; Table 3 ). This was associated with an apparent increase in serum $\mathrm{FxOH}(P<0.0001)$, a metabolite 


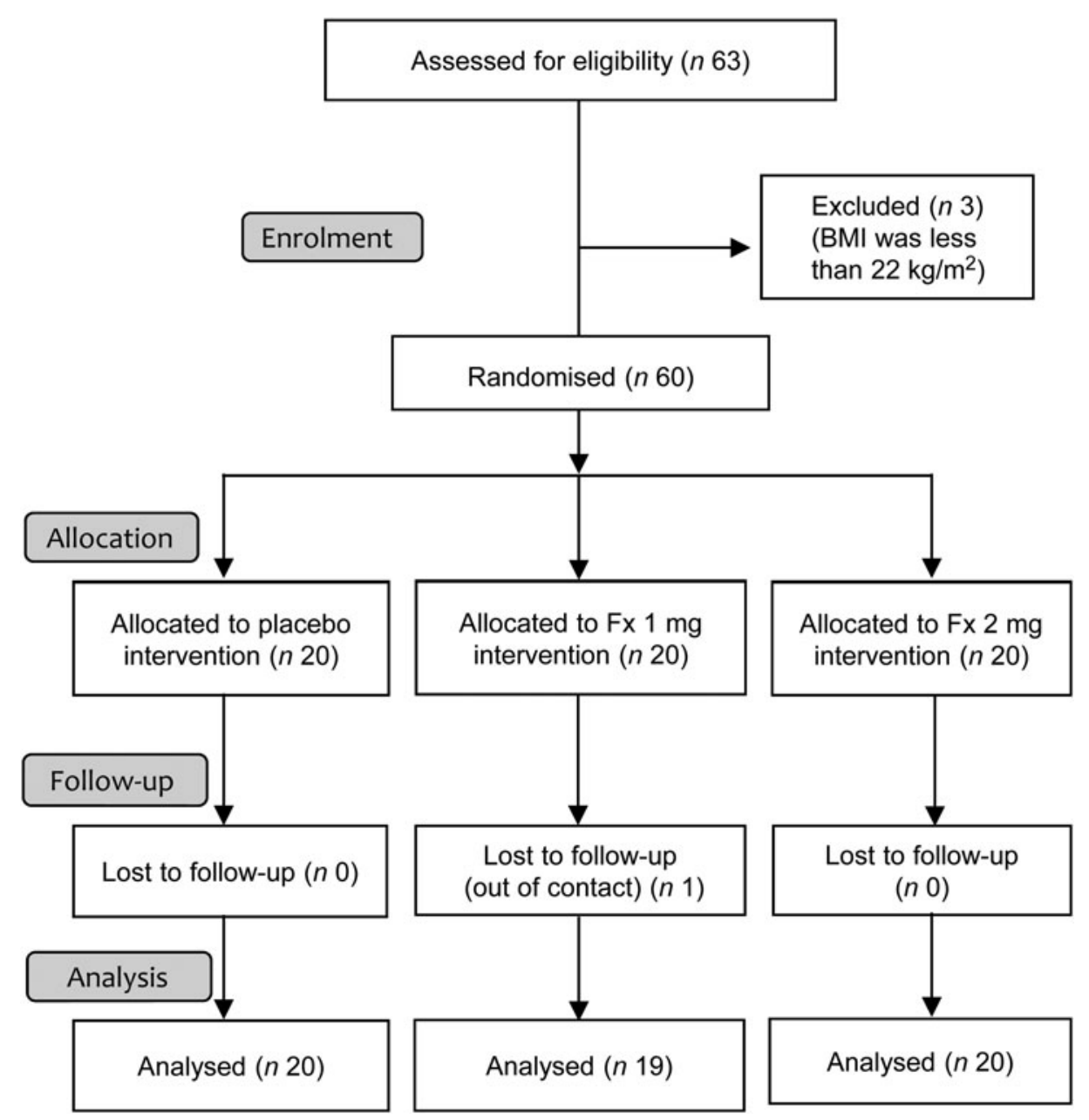

Fig. 1. Flow diagram of Japanese adult subjects enrolled in the fucoxanthin $(\mathrm{Fx})$ clinical trial. Subjects were randomised, allocated to $\mathrm{Fx}$ intervention groups $(0,1$ or $2 \mathrm{mg} / \mathrm{d}$ ) and followed up for 8 weeks.

of Fx (Table 3). Indeed, significant increases in serum $\mathrm{FxOH}$ levels detected between the $1 \mathrm{mg} / \mathrm{d}$ and $0 \mathrm{mg} / \mathrm{d}$ groups $(P<$ $0.0001)$, and between the $2 \mathrm{mg} / \mathrm{d}$ and $0 \mathrm{mg} / \mathrm{d}$ groups $(P<$ $0 \cdot 0001$ ) indicated a dose-dependent effect (Table 3), with mean FxOH levels of 2.7 and 2.1 and $0.4 \mathrm{~nm}$, for the 2, 1 and $0 \mathrm{mg} / \mathrm{d}$ groups, respectively.

\section{Possible interaction between fucoxanthin supplementation and UCP1-3826A/G polymorphism may influence reduction of HbAIC}

As shown in Fig. 2(A), 8 weeks of supplementation with $2 \mathrm{mg} / \mathrm{d}$ of Fx significantly reduced HbA1c levels in subjects with the UCP1-3826A/G polymorphism. The reduction in HbA1c levels for the G/G genotype (-0.54 (SE 0.45) \%) was significantly greater than that of the A/A $(0.05$ (SE $0.17) \%, P<0.05)$ and $\mathrm{A} / \mathrm{G}(-0.02(\mathrm{se} 0.18) \%, P<0.01)$ genotypes. We noted that the sample number for each UCP1-3826A/G genotype was not significantly different among $F_{x}$ groups $(P=0.63$, Fisher's exact test), and that HbA1c levels did not decline in the $\mathrm{Fx} 0$ or $1 \mathrm{mg} / \mathrm{d}$ groups (Fig. 2(A)). Additionally, serum FxOH levels were not affected by the UCP1 genotype (Supplementary Fig. S1). Parallel plot analysis confirmed that $\mathrm{Fx}$ intervention reduced $\mathrm{HbA} 1 \mathrm{c}$ and glycated albumin levels in all Fx $2 \mathrm{mg} / \mathrm{d}$ participants who carried the $U C P 1 \mathrm{G} / \mathrm{G}$ allele. $P$ values from the paired $t$ test for changes in $\mathrm{HbA} 1 \mathrm{c}$ and glycated albumin (before intervention $v$. after intervention) were 0.055 and 0.067 , respectively (Fig. 2(B)). We could not analyse the involvement of other well-known thrifty genes, such as $\beta 3 A R \quad 64 \mathrm{Trp} / \operatorname{Arg}$ and $\beta 2 A \mathrm{R}$ Arg/Gly, with Fx-induced reduction of $\mathrm{HbA} 1 \mathrm{c}$ because of the lack of carriers for each genotype (Fig. 3).

\section{Baseline parameters were unbiased according to UCP1 genotype}

Table 4 shows the baseline characteristics of each UCP1 genotype group. At baseline, the participants of each genotype were evenly distributed in terms of age, sex, BMI, visceral fat area, REE and all blood biochemical markers.

\section{Safety}

In the present study, Fx capsules were well tolerated by all participants who completed the 8-week trial. No subjective or 
Table 2. Obesity-related parameters for Japanese adults in the fucoxanthin ( $F x)$ intervention groups ( 0 or 1 or $2 \mathrm{mg} / \mathrm{d})$ at baseline and after intervention*

(Mean values with their standard errors)

\begin{tabular}{|c|c|c|c|c|c|c|c|c|c|c|c|c|c|c|c|c|c|}
\hline & \multicolumn{7}{|c|}{ Baseline } & \multicolumn{7}{|c|}{ After } & \multirow{2}{*}{\multicolumn{3}{|c|}{$\begin{array}{l}\text { Baseline } v \text {. after } \\
\text { Within group }(P)\end{array}$}} \\
\hline & \multicolumn{2}{|c|}{ Fx $0 \mathrm{mg}$} & \multicolumn{2}{|c|}{ Fx $1 \mathrm{mg}$} & \multicolumn{2}{|c|}{ Fx $2 \mathrm{mg}$} & \multirow[b]{2}{*}{$P$} & \multicolumn{2}{|c|}{ Fx $0 \mathrm{mg}$} & \multicolumn{2}{|c|}{ Fx $1 \mathrm{mg}$} & \multicolumn{2}{|c|}{ Fx $2 \mathrm{mg}$} & \multirow[b]{2}{*}{$P$} & & & \\
\hline & Mean & SE & Mean & SE & Mean & SE & & Mean & SE & Mean & SE & Mean & SE & & Fx $0 \mathrm{mg}$ & Fx $1 \mathrm{mg}$ & $\mathrm{F} \times 2 \mathrm{mg}$ \\
\hline Subjects & & & & & & & 0.24 & & & & & & & & & & \\
\hline Number & 20 & & 19 & & 20 & & & & & & & & & & & & \\
\hline Male \% & 20 & & 32 & & 45 & & & & & & & & & & & & \\
\hline Age (years) & 53.0 & $2 \cdot 2$ & 57.5 & $2 \cdot 9$ & $55 \cdot 2$ & $3 \cdot 2$ & 0.52 & & & & & & & & & & \\
\hline Height (cm) & $157 \cdot 6$ & 1.7 & $158 \cdot 2$ & 1.8 & 159.9 & 2.4 & 0.68 & & & & & & & & & & \\
\hline Weight (kg) & 62.8 & $2 \cdot 0$ & 67.0 & 3.3 & $70 \cdot 2$ & 3.3 & 0.23 & 64.2 & 2.5 & 64.6 & 3.4 & $70 \cdot 1$ & 3.4 & 0.28 & 0.90 & 0.90 & 0.87 \\
\hline BMI $\left(\mathrm{kg} / \mathrm{m}^{2}\right)$ & $25 \cdot 2$ & 0.5 & $26 \cdot 6$ & 0.9 & $27 \cdot 2$ & 0.7 & 0.06 & $25 \cdot 1$ & 0.5 & $26 \cdot 3$ & 0.9 & $26 \cdot 9$ & 0.7 & 0.17 & 0.95 & 0.79 & 0.82 \\
\hline Visceral fat area $\left(\mathrm{cm}^{2}\right)$ & 91.6 & 9.0 & 119.4 & 17.4 & 113.5 & 8.3 & 0.24 & 85.0 & $7 \cdot 7$ & 110.8 & 14.6 & $107 \cdot 8$ & 7.8 & 0.09 & 0.58 & 0.80 & 0.62 \\
\hline Resting energy expenditure $(\mathrm{kcal} / \mathrm{d}) \dagger$ & 1342 & 58 & 1326 & 76 & 1467 & 108 & 0.54 & 1400 & 52 & 1383 & 65 & 1561 & 97 & 0.18 & 0.46 & 0.58 & 0.42 \\
\hline \multicolumn{18}{|l|}{ Blood biochemistry } \\
\hline Glucose (mg/dl)† & 109 & 7 & 107 & 3 & 111 & 3 & 0.19 & 106 & 7 & 108 & 5 & 105 & 3 & 0.26 & 0.06 & 1.00 & 0.13 \\
\hline $\mathrm{HbA} 1 \mathrm{c}(\%)$ & 5.4 & 0.3 & $5 \cdot 2$ & 0.1 & $5 \cdot 2$ & 0.1 & 0.61 & 5.4 & 0.2 & $5 \cdot 2$ & 0.1 & $5 \cdot 1$ & 0.1 & 0.33 & 0.28 & 0.94 & 0.32 \\
\hline Insulin $(\mu \mathrm{U} / \mathrm{ml})$ & 8.2 & 0.7 & 8.3 & 0.8 & 8.8 & 1.1 & 0.98 & 7.0 & 0.7 & 7.9 & 0.8 & 8.3 & 0.9 & 0.51 & 0.16 & 0.69 & 0.86 \\
\hline Total cholesterol $(\mathrm{mg} / \mathrm{dl}) \dagger$ & 207 & 8 & 210 & 9 & 205 & 10 & 0.93 & 216 & 9 & 216 & 9 & 205 & 9 & 0.54 & 0.43 & 0.66 & 0.94 \\
\hline HDL-cholesterol (mg/dl)† & 59 & 2 & 57 & 2 & 57 & 3 & 0.80 & 60 & 3 & 57 & 2 & 60 & 3 & 0.82 & 0.99 & 0.93 & 0.59 \\
\hline LDL-cholesterol (mg/dl)† & 121 & 8 & 118 & 7 & 122 & 8 & 0.95 & 130 & 8 & 129 & 8 & 119 & 9 & 0.59 & 0.45 & 0.31 & 0.84 \\
\hline $\mathrm{TAG}(\mathrm{mg} / \mathrm{dl}) \dagger$ & 129 & 15 & 177 & 46 & 132 & 24 & 0.23 & 132 & 17 & 130 & 15 & 141 & 28 & 0.77 & 0.97 & 0.81 & 0.84 \\
\hline Aspartate aminotransferase (IU) & 21 & 2 & 21 & 1 & 24 & 2 & 0.56 & 21 & 2 & 22 & 2 & 24 & 2 & 0.79 & 0.86 & 0.72 & 0.62 \\
\hline Alanine aminotransferase (IU) & 21 & 2 & 23 & 2 & 30 & 5 & 0.31 & 21 & 2 & 23 & 3 & 28 & 5 & 0.55 & 0.95 & 0.81 & 0.78 \\
\hline$\gamma$-Glutamyl transpeptidase (IU) & 47 & 18 & 33 & 6 & 44 & 11 & 0.77 & 43 & 13 & 32 & 5 & 46 & 14 & 0.90 & 0.77 & 0.86 & 1.00 \\
\hline
\end{tabular}

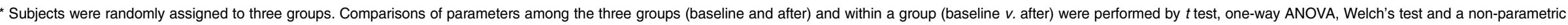
Steel-Dwass test. No significant differences were observed between and within the three groups.

† To convert kcal to $\mathrm{kJ}$, multiply by 4.184 ; to convert glucose from $\mathrm{mg} / \mathrm{dl}$ to $\mathrm{mmol} / \mathrm{l}$, multiply by 0.0555 ; to convert cholesterol from $\mathrm{mg} / \mathrm{dl}$ to $\mathrm{mmol} / \mathrm{l}$, multiply by 0.0259 ; to convert TAG from $\mathrm{mg} / \mathrm{dl}$ to $\mathrm{mmol} / \mathrm{l}$, multiply by 0.0113 . 
Table 3. Changes in HbA1c levels and serum fucoxanthinol ( $\mathrm{FxOH})$ levels in the fucoxanthin ( $F x)$ intervention groups $(0$ or 1 or $2 \mathrm{mg} / \mathrm{d})$ after the 8-week intervention $\dagger$ (Mean values with their standard errors)

\begin{tabular}{|c|c|c|c|c|c|c|}
\hline & \multicolumn{2}{|c|}{ Fx $0 \mathrm{mg}$} & \multicolumn{2}{|c|}{$\mathrm{Fx} 1 \mathrm{mg}$} & \multicolumn{2}{|c|}{$\mathrm{Fx} 2 \mathrm{mg}$} \\
\hline & Mean & SE & Mean & SE & Mean & SE \\
\hline$\Delta \mathrm{HbA} 1 \mathrm{c}(\%)$ & 0.06 & 0.05 & 0.01 & 0.05 & $-0.14^{\star}$ & 0.05 \\
\hline $\begin{array}{l}\text { Serum FxOH levels } \\
\quad \text { (after } 8 \text { weeks) (nм) }\end{array}$ & 0.4 & 0.0 & $2 \cdot 1^{* *}$ & 0.2 & $2 \cdot 7^{\star *}$ & 0.4 \\
\hline
\end{tabular}

Mean value was significantly different from that of the $0 \mathrm{mg} / \mathrm{d}$ group: ${ }^{*} P<0.05$, ** $P<0.0001$.

$\dagger \triangle \mathrm{HbA} 1 \mathrm{c}$ represents the change in $\mathrm{HbA} 1 \mathrm{c}$ levels before and after an 8-week intervention of $\mathrm{Fx}$. $P$ values for comparison of parameters among the three groups were calculated by one-way ANOVA, the Tukey-Kramer test for multiple comparisons and a non-parametric Steel-Dwass test.

(A)
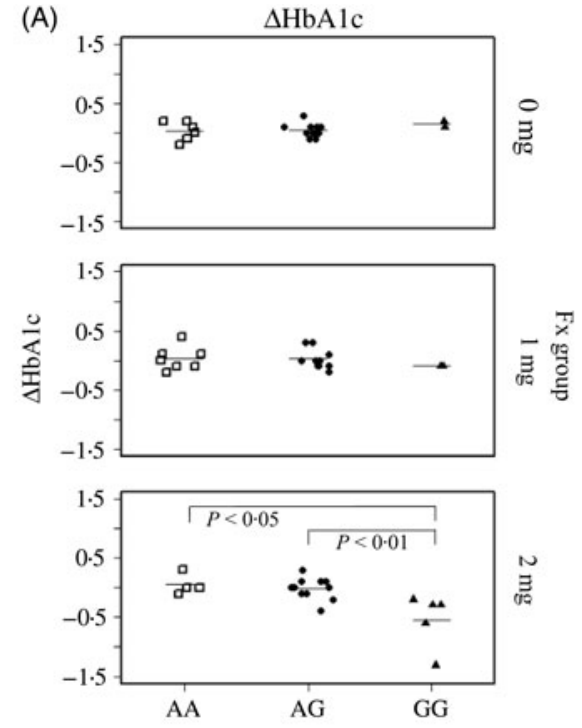

(B)

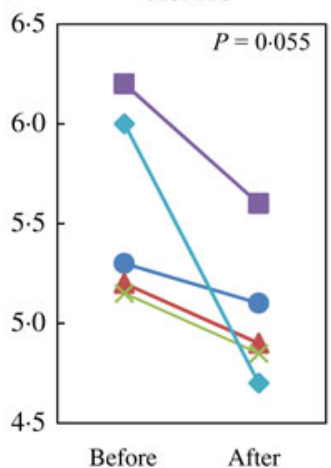

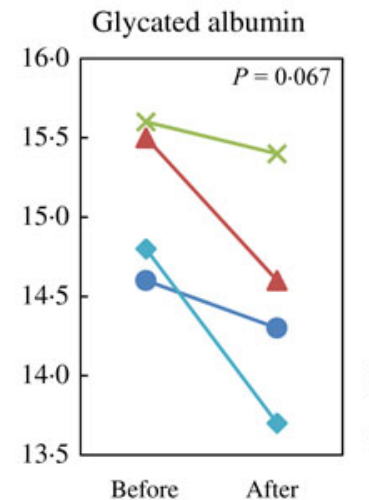

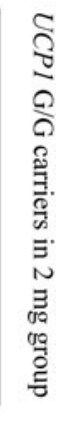

Fig. 2. Reduction in $\mathrm{HbA} 1 \mathrm{c}$ levels after 8 weeks of fucoxanthin (Fx) treatment with possible involvement of the thrifty allele of uncoupling protein 1 (UCP1) in Japanese adults. (A) $\triangle \mathrm{HbA1c}$ with $U C P 1-3826 \mathrm{~A} / \mathrm{G}$ genotype. In the $2 \mathrm{mg} / \mathrm{d}$ group: $\mathrm{A} / \mathrm{A}$ v. $\mathrm{G} / \mathrm{G}(P<0.05)$ and $\mathrm{A} / \mathrm{G}$ v. $\mathrm{G} / \mathrm{G}(P<0.01)$. (B) Changes in $\mathrm{HbA} 1 \mathrm{c}$ levels and glycated albumin before and after the 8-week intervention in $\mathrm{G} / \mathrm{G}$ genotype carriers of the $2 \mathrm{mg} / \mathrm{d}$ group $(n 5)$. Both $\mathrm{HbA} 1 \mathrm{c}$ and glycated albumin levels declined for all $\mathrm{G} / \mathrm{G}$ genotype carriers in the $2 \mathrm{mg} / \mathrm{d}$ group. Paired $t$ tests for comparisons of the changes in $\mathrm{HbA1c}$ and glycated albumin levels (before and after intervention) yielded $P=0.055$ and $P=0.067$, respectively. Glycated albumin levels from one subject could not be determined because of a lack of sample volume. objective adverse effects, including hepatic dysfunction and alterations in lipid metabolism, were reported.

\section{Discussion}

Our present study showed that intake of Fx-enriched akamoku oil significantly increased serum $\mathrm{FxOH}$ levels in a fashion of Fx dose-dependency. The increase was associated with HbA1c reduction, remarkably in carriers with the $G / G$ allele of the UCP1 gene. These results suggest that Fx intake affects $\mathrm{HbA} 1 \mathrm{c}$ reduction in UCP1 polymorphism. Further studies are needed to elucidate a mechanistic link between Fx intake and glucose metabolism in $\mathrm{G} / \mathrm{G}$ allele carriers.

Genetic variations generate innate characteristics in individuals and the population, as shown by genome-wide association studies $^{(21)}$. Because of the great diversity and complexity of genetic backgrounds, tailoring healthcare through the use of rational genotyping such as SNP analysis is rising in importance. For instance, the thrifty UCP1 G/G genotype is one of the most well-characterised genes associated with the development of obesity and insulin resistance ${ }^{(12)}$. It is conceivable that carriers of the $\mathrm{G} / \mathrm{G}$ allele, comprising over $20 \%$ of the East Asian population $^{(22,23)}$, could be at high risk for obesity-related disorders. It is also possible that carriers of the $G / G$ allele may respond to treatment differently from the general population. For that reason, we aimed to elucidate the biofunctional effects of Fx on metabolic disorders in the Japanese population.

Our study was a single-blinded, randomised controlled clinical trial. In all, sixty participants were assigned to three groups (n 20 per group): 0,1 or $2 \mathrm{mg} / \mathrm{d}$ of $\mathrm{Fx}$ per $\mathrm{d}$ for 8 weeks. Contrary to a previous report in mice ${ }^{(24)}$, no adverse effects involving serum biochemical markers of the liver and lipid dysfunction were reported.

In a previous study, 8 weeks of supplementation with Xanthigen $^{\circledR}$ (containing Fx and pomegranate seed oil) decreased the body weight of Russian women ${ }^{(9)}$. However, those results were not reproduced in our study. Indeed, we detected no changes in obesity-related outcomes, including visceral fat area, which could be explained by the many differences between the two study populations (e.g. race, sex, age, body weight and BMI). Further, the reduced body weight in Russian women could have been related to the combined effects of Xanthigen ${ }^{\circledR}$ including $\mathrm{Fx}_{\mathrm{X}}$ and pomegranate seed oil.

Orally administered Fx is hydrolysed to FxOH in the intestinal tract, after which it is absorbed ${ }^{(18)}$ and detected in the blood and organs ${ }^{(25)}$. We noted a dose-dependent increase in serum $\mathrm{FxOH}$ that confirmed oral absorption of $\mathrm{Fx}$. Combined with the reduction of $\mathrm{HbA1c}$ for the $2 \mathrm{mg} / \mathrm{d}$ group (but not the $0 \mathrm{mg} / \mathrm{d}$ group), our results strongly suggest that Fx possesses biofunctionality.

Furthermore, we determined that $\mathrm{HbA1c}$ reduction was closely linked to the $\mathrm{G} / \mathrm{G}$ allele of the UCP1 gene. Participants in the $2 \mathrm{mg} / \mathrm{d}$ group who carried the UCP1-3826A/G gene polymorphism exhibited a more appreciable reduction in $\mathrm{HbA1c}$ levels. HbA1c, glycated $\mathrm{Hb}$ that reflects average blood glucose levels, is considered the standard for assessing glucose metabolism over the long term. Additionally, serum levels of glycated albumin (a product of 
(A)
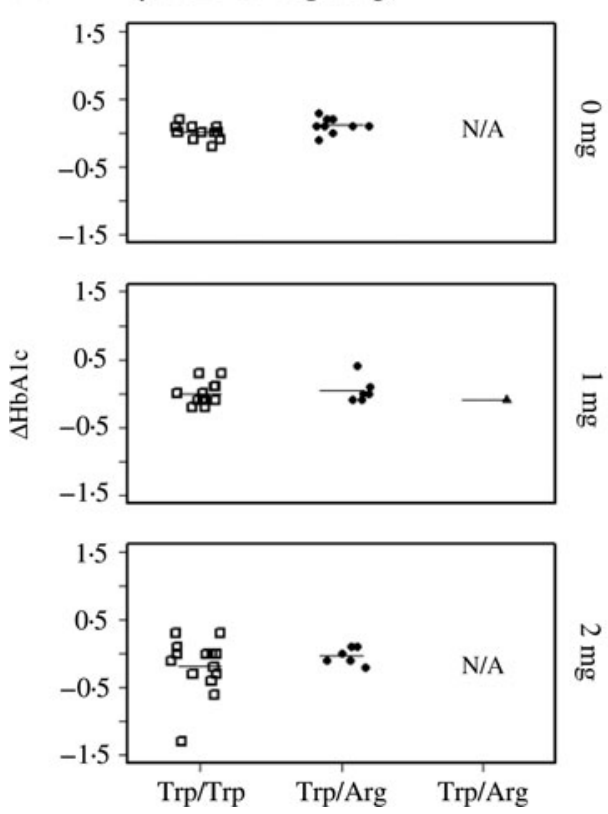

(B) B2AR 64 Arg/Gly
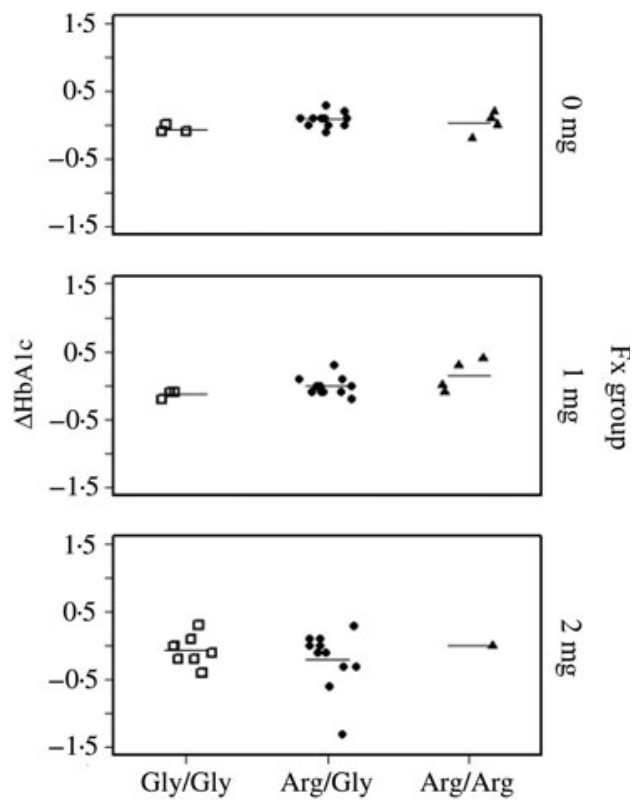

Fig. 3. Effects of other well-known thrifty genotypes on 8-week fucoxanthin (Fx)-induced changes in $\mathrm{HbA1c}$ levels in Japanese adults. $\Delta \mathrm{HbA1c}$ in subjects with (A) $\beta 3$-adrenoreceptor $(\beta 3 A R) 64 \mathrm{Trp} / \mathrm{Arg}$ and $(\mathrm{B}) \beta 2$-adrenoreceptor $(\beta 2 A R)$ Arg/Gly polymorphisms. We were unable to observe the effect of these two polymorphisms on Fx-induced reduction of HbA1c levels because of the limited number of carriers with each genotype. N/A, not applicable.

Table 4. Baseline characteristics of trial subjects stratified into three genotypes of uncoupling protein 1 (UCP1)-3826A/G polymorphism in Japanese adults* (Mean values with their standard errors)

\begin{tabular}{|c|c|c|c|c|c|c|c|}
\hline \multirow[t]{2}{*}{ UCP1-3826A/G genotype... } & \multicolumn{2}{|c|}{$\mathrm{A} / \mathrm{A}$} & \multicolumn{2}{|c|}{$A / G$} & \multicolumn{2}{|c|}{$\mathrm{G} / \mathrm{G}$} & \multirow[b]{2}{*}{$P$} \\
\hline & Mean & $\mathrm{SE}$ & Mean & $\mathrm{SE}$ & Mean & SE & \\
\hline \multicolumn{8}{|l|}{ Subjects } \\
\hline Number & 17 & & 33 & & 9 & & 0.54 \\
\hline Male \% & 24 & & 33 & & 44 & & \\
\hline Age (years) & $55 \cdot 1$ & 3.2 & 54.7 & 2.2 & $57 \cdot 1$ & 3.7 & 0.88 \\
\hline Weight (kg) & $66 \cdot 0$ & 3.9 & $66 \cdot 6$ & $2 \cdot 1$ & $68 \cdot 2$ & 4.0 & 0.86 \\
\hline BMI $\left(\mathrm{kg} / \mathrm{m}^{2}\right)$ & $25 \cdot 6$ & 0.8 & $26 \cdot 8$ & 0.6 & 25.9 & 0.7 & 0.48 \\
\hline Visceral fat area $\left(\mathrm{cm}^{2}\right)$ & 88.6 & 8.8 & $112 \cdot 2$ & $10 \cdot 8$ & $129 \cdot 2$ & 13.5 & 0.14 \\
\hline Resting energy expenditure $(\mathrm{kcal} / \mathrm{d}) \dagger$ & 1388 & 113 & 1340 & 57 & 1504 & 107 & 0.43 \\
\hline \multicolumn{8}{|l|}{ Blood biochemistry } \\
\hline Glucose $(\mathrm{mg} / \mathrm{dll}) \dagger$ & 112 & 8 & 108 & 2 & 109 & 4 & 0.57 \\
\hline $\mathrm{HbA1c}(\%)$ & 5.4 & 0.3 & $5 \cdot 2$ & 0.1 & 5.4 & 0.2 & 0.29 \\
\hline Insulin $(\mu \mathrm{U} / \mathrm{ml})$ & $7 \cdot 1$ & 0.9 & $9 \cdot 0$ & 0.7 & 8.6 & 1.4 & 0.18 \\
\hline Total cholesterol $(\mathrm{mg} / \mathrm{dl}) \dagger$ & 209 & 10 & 211 & 7 & 191 & 13 & 0.39 \\
\hline HDL-cholesterol (mg/dl) $\dagger$ & 58 & 3 & 58 & 2 & 57 & 3 & 0.92 \\
\hline LDL-cholesterol (mg/dl) $\dagger$ & 120 & 10 & 123 & 5 & 111 & 14 & 0.46 \\
\hline TAG $(\mathrm{mg} / \mathrm{dl}) \dagger$ & 142 & 20 & 152 & 29 & 127 & 25 & 0.83 \\
\hline Aspartate aminotransferase (IU) & 20 & 2 & 21 & 1 & 28 & 4 & 0.08 \\
\hline Alanine aminotransferase (IU) & 24 & 5 & 22 & 2 & 33 & 7 & 0.19 \\
\hline$\gamma$-Glutamyl transpeptidase (IU) & 36 & 7 & 40 & 11 & 57 & 23 & 0.38 \\
\hline
\end{tabular}

* Subjects were stratified into three genotypes of UCP1. P values for comparison of parameters among the three genotypes were calculated using one-way ANOVA, Welch's test and a non-parametric Steel-Dwass test. No significant differences were found.

$\dagger$ To convert kcal to $\mathrm{kJ}$, multiply by 4.184 ; to convert glucose from $\mathrm{mg} / \mathrm{dl}$ to $\mathrm{mmol} / \mathrm{l}$, multiply by 0.0555 ; to convert cholesterol from $\mathrm{mg} / \mathrm{dl}$ to $\mathrm{mmol} / \mathrm{l}$, $\mathrm{multiply} \mathrm{by} 0.0259$; to convert TAG from $\mathrm{mg} / \mathrm{dl}$ to $\mathrm{mmol} / \mathrm{l}$, multiply by 0.0113 .

non-enzymic glycation that is also used as a glycaemic indicator) apparently decreased in all subjects in the $2 \mathrm{mg} / \mathrm{d}$ group with the $G / G$ genotype. Although an accurate HbA1c measurement is limited by various conditions, including erythrocyte lifespan, normal ageing and other factors ${ }^{(26)}$, the decline in both $\mathrm{HbA} 1 \mathrm{c}$ and glycated albumin levels suggests that $\mathrm{Fx}$ may aid in glucose metabolism. Taken together, our findings indicate a novel role for Fx: UCP1 genotype-dependent reduction of HbA1c levels in humans, although the mechanism by which Fx exerts this effect remains unclear.

There are other reports supporting a relationship between Fx and UCP1 gene products: UCP1 mRNA expression levels in human intraperitoneal adipose tissue are lower in $U C P 1 \mathrm{G} / \mathrm{G}$ genotype carriers than in the other two genotypes ${ }^{(27)}$; and $\mathrm{Fx}$ 
induces $U C P 1 \mathrm{mRNA}$ and protein expression in murine adipocytes $^{(3)}$. To expand upon our findings on the relationship between Fx and the UCP1 genotype, further studies with more participants are needed. In addition, various formulations of $\mathrm{Fx}$ or $\mathrm{FxOH}$ might be investigated in addition to Fx oil, such as processed algal materials, food matrix-destruction, mixing with lysoglyceroglycolipids ${ }^{(28)}$, and/or addition of egg yolk to $\mathrm{FxOH}^{(29)}$.

Our data indicate that Fx-induced reduction of $\mathrm{HbA1c}$ levels is closely linked to the $G / G$ allele of the UCP1 gene. Fx's dependence on UCP1 gene polymorphism sheds light on a possible tailored application for this unique carotenoid. Indeed, tailoring a nutraceutical like Fx would be a rational and efficient treatment strategy for genetically high-risk populations.

\section{Supplementary material}

The supplementary material for this article can be found at https://doi.org/10.1017/jns.2017.1

\section{Acknowledgements}

We wish to express our appreciation to the study participants in the Rumoi area. We also thank Mr Ryo Susukida and Mr Tomoyuki Satake for technical assistance with the measurement of biological parameters, and Ms Miho Onishi for assistance with implementation of the clinical trial in the local area. We are indebted for the valuable information about SNP provided by Professor Akihiro Sakurai of the Sapporo Medical University School of Medicine.

This work was supported by the National Project for the Formation of Tohoku Marine Science Center (Innovation Strategy for the Industrial Seaweed Utilisation Supporting Regional Seeds and Local Features of Sanriku Coast) from the Ministry of Education, Culture, Sports, Science, and Technology of Japan, and the Japan Society for the Promotion of Science Grants-in-Aid (JSPS KAKENHI grant number JP16K21251).

N. M. designed the research, analysed and interpreted the data, and wrote the manuscript. M. H. and K. M. formulated the study conception and revised the manuscript. H. S. interpreted the data and wrote the manuscript. Y. M. I. interpreted and reviewed statistical analysis of the data. Y. K. supervised the work, designed the research, interpreted data and wrote the manuscript. All authors read and approved the final manuscript.

There were no conflicts of interest.

\section{References}

1. Liaaen-Jensen S (1978) Marine carotenoids. In Marine Natural Products. Chemical and Biochemical Perspective, vol. 2, pp. 1-73 [PJ Scheuer, editor]. New York: Academic Press.

2. Terasaki M, Hirose A, Narayan B, et al. (2009) Evaluation of recoverable functional lipid components of several brown seaweeds (Phaeophyta) from Japan with special reference to fucoxanthin and fucosterol contents. J Phycol 45, 974-980.

3. Maeda H, Hosokawa M, Sashima T, et al. (2005) Fucoxanthin from edible seaweed, Undaria pinnatifida, shows antiobesity effect through
UCP1 expression in white adipose tissues. Biochem Biophys Res Commun 332, 392-397.

4. Woo MN, Jeon SM, Shin YC, et al. (2009) Anti-obese property of fucoxanthin is partly mediated by altering lipid-regulating enzymes and uncoupling proteins of visceral adipose tissue in mice. Mol Nutr Food Res 53, 1603-1611.

5. Nishikawa S, Hosokawa M, Miyashita K (2012) Fucoxanthin promotes translocation and induction of glucose transporter 4 in skeletal muscles of diabetic/obese KK-A(y) mice. Phytomedicine 19, 389-394.

6. Kotake-Nara E, Terasaki M, Nagao A (2005) Characterization of apoptosis induced by fucoxanthin in human promyelocytic leukemia cells. Biosci Biotechnol Biochem 69, 224-227.

7. Hashimoto T, Ozaki Y, Mizuno M, et al. (2012) Pharmacokinetics of fucoxanthinol in human plasma after the oral administration of kombu extract. Br J Nutr 107, 1566-1569.

8. Asai A, Yonekura L, Nagao A (2008) Low bioavailability of dietary epoxyxanthophylls in humans. Br J Nutr 100, 273-277.

9. Abidov M, Ramazanov Z, Seifulla R, et al. (2010) The effects of Xanthigen in the weight management of obese premenopausal women with non-alcoholic fatty liver disease and normal liver fat. Diabetes Obes Metab 12, 72-81.

10. Walston J, Silver K, Bogardus C, et al. (1995) Time of onset of non-insulin-dependent diabetes mellitus and genetic variation in the $\beta 3$-adrenergic-receptor gene. $N$ Engl J Med 333, 343-347.

11. Cassard-Doulcier AM, Bouillaud F, Chagnon M, et al. (1996) The Bcl I polymorphism of the human uncoupling protein (UCP) gene is due to a point mutation in the $5^{\prime}$-flanking region. Int $J$ Obes Relat Metab Disord 20, 278-279.

12. Bracale R, Labruna G, Finelli C, et al. (2012) The absence of polymorphisms in ADRB3, UCP1, PPAR $\gamma$, and ADIPOQ genes protects morbid obese patients toward insulin resistance. J Endocrinol Invest 35, 2-4.

13. Sakane N, Yoshida T, Umekawa T, et al. (1999) $\beta_{2}$-Adrenoceptor gene polymorphism and obesity. Lancet 353, 1976.

14. Yoshida T, Sakane N, Umekawa T, et al. (1995) Mutation of $\beta 3$-adrenergic-receptor gene and response to treatment of obesity. Lancet 346, 1433-1434.

15. Tate DF, Jackvony EH, Wing RR (2003) Effects of Internet behavioral counseling on weight loss in adults at risk for type 2 diabetes: a randomized trial. JAMA 289, 1833-1836.

16. McDoniel SO (2007) Systematic review on use of a handheld indirect calorimeter to assess energy needs in adults and children. Int $J$ Sport Nutr Exerc Metab 17, 491-500.

17. Luconi M, Nreu B, Samavat J, et al. (2016) Is early measurement of glycated albumin and $\mathrm{HbA1c}$ useful for the prediction of treatment response in type 2 diabetes? Acta Diabetol 53, 669-672.

18. Sugawara T, Baskaran V, Tsuzuki W, et al. (2002) Brown algae fucoxanthin is hydrolyzed to fucoxanthinol during absorption by Caco-2 human intestinal cells and mice. J Nutr 132, 946-951.

19. Yamada Y, Izawa H, Ichihara S, et al. (2002) Prediction of the risk of myocardial infarction from polymorphisms in candidate genes. N Engl J Med 347, 1916-1923.

20. Ogawa W \& Miyazaki S (2015) Diagnosis criteria for obesity and obesity disease. HEP 42, 301-306.

21. Shungin D, Winkler TW, Croteau-Chonka DC, et al. (2015) New genetic loci link adipose and insulin biology to body fat distribution. Nature 518, 187-196.

22. Yoneshiro T, Ogawa T, Okamoto N, et al. (2013) Impact of UCP1 and $\beta 3 \mathrm{AR}$ gene polymorphisms on age-related changes in brown adipose tissue and adiposity in humans. Int J Obes 37, 993-998.

23. Oh HH, Kim KS, Choi SM, et al. (2004) The effects of uncoupling protein-1 genotype on lipoprotein cholesterol level in Korean obese subjects. Metabolism 53, 1054-1059.

24. Beppu F, Hosokawa M, Niwano Y, et al. (2012) Effects of dietary fucoxanthin on cholesterol metabolism in diabetic/obese KK-A(y) mice. Lipids Health Dis 11, 112.

25. Hashimoto T, Ozaki Y, Taminato M, et al. (2009) The distribution and accumulation of fucoxanthin and its metabolites after oral administration in mice. Br J Nutr 102, 242-248. 
26. Shepard JG, Airee A, Dake AW, et al. (2015) Limitations of A1c interpretation. South Med J 108, 724-729.

27. Esterbauer H, Oberkofler H, Liu YM, et al. (1998) Uncoupling protein-1 mRNA expression in obese human subjects: the role of sequence variations at the uncoupling protein-1 gene locus. J Lipid Res 39, 834-844.
28. Kotake-Nara E, Yonekura L \& Nagao A (2015) Lysoglyceroglycolipids improve the intestinal absorption of micellar fucoxanthin by Caco-2 cells. J Oleo Sci 64, 1207-1211.

29. Strand A, Herstad O \& Liaaen-Jensen S (1998) Fucoxanthin metabolites in egg yolks of laying hens. Comp Biochem Physiol A Mol Integr Physiol 119, 963-974. 